\title{
Quality of life among the elderly in suburban Hanoi, Vietnam: Needs assessment and socio-economic factors affecting the elderly care
}

\author{
Dung Nguyen Tien, Zhang Guangli* \\ Social and Public Administration School of Ecust, Shanghai, China \\ nguyentiendung.qtkd@gmail.com
}

Keywords: Vietnam, population, elderly care, socio-economic factors.

\begin{abstract}
Vietnam is entering a period of population aging with major challenges. Increasing number of elderly people require care, both physically and mentally. According to statistics, Vietnam's population is "aging" very quickly at a rate unprecedented in history, the fastest in Asia. According to data from the Ministry of Health (2015), the elderly in Vietnam accounted for 10.5\% of the national population. It is noteworthy that the average life expectancy of Vietnam has increased but the number of years of healthy life is quite low. Only about $5 \%$ of the country's elderly people are in good health, the remaining 95\% bring in their health many diseases such as hypertension, arthritis, lung disease-chronic obstructive bronchitis, diabetes, dementia... The labor movement from rural to urban areas in the working age to work and the impact of the socio-economic changes make older people more than the actual age and older people increasingly get less support from family. This study aimed to find out the needs of daily care and the socio-economic factors affecting the elderly in suburban areas of Hanoi.
\end{abstract}

\section{Introduction}

Trends rapidly aging population, a reduction in the birth and death rate is statistically in Vietnam in over recent 3 decades. The proportion of people aged 60 and older increased from $6.7 \%$ in 1979 has increased by $10.5 \%$ in 2015 and forecasted to be $26.1 \%$ in 2050. The average life expectancy of Vietnam increased from 66 in 1990 to 73.2 years old in 2014 and is expected to increase to 82 in 2050 (GSO 2015). Forecasts to 2050, the elderly population in Vietnam will increase by nearly 4 times up to $23 \%$ of the total population (Population forecast Vietnam - GSO 2015). In other words, within 35 years, about a quarter of the population is elderly. The average population of Vietnam in 2014 was 90.73 million, up $1.08 \%$ compared to 2013, in which population in urban is 30.04 million (33.1\%) and rural is 60.69 million (66.9\%). Most of populations live in rural areas with more difficult life. These elderly in rural areas are more likely to need the economic support for the social security system. Temporary migration trend from rural to urban areas to work, especially in urban neighborhoods, to seek better jobs are increasing sharply. This leads to many social implications in which older people receive less the material and spiritual support from the members is a typical.

This study will assess needs daily care and socio-economic factors that affect the elderly health care in outside of Hanoi.

\section{Methodology, Research design, sampling and sample size}

The study was conducted as part of a larger study in 2016. Data was collected in the system demographic and health monitoring through a survey in three suburban districts of Hanoi, Vietnam. Chuong My is a suburb district located in the southwest of Hanoi, $20 \mathrm{~km}$ far from the center of the capital, $237.4 \mathrm{~km} 2$ natural, 337,600 population, including 31 communes and communal 2 towns. Hoai Duc district is located in the west of central Hanoi with 20 administrative units attached, 82.38 $\mathrm{km}^{2}$ natural; 190,612 populations. Dong Anh is a suburban district of Hanoi, $15 \mathrm{~km}$ far from the city center to the north with an area of $182.3 \mathrm{~km}^{2}$ naturally, the population in 2014 is 375,000 . 
Research surveys of representative samples of 15 randomly selected clusters. A cluster is defined as an administrative unit (commune).

A household survey was conducted. The sample size was calculated based on the estimated rate of population censuses in 2014 by the General Statistics Office implemented. Use ratio estimated 11\% of the elderly - who need support for daily life in rural Vietnam, the sample size of 3981 elderly people was required. Then, 50\% of households with elderly people were randomly selected for a household survey. Face to face interviews were conducted with all the elders and their families represented in the selected households (this includes 1990 people). During the survey from March to August 2016, there were 227 households have been excluded due to the absence of older people. A total of 1763 adults were included in the study.

\section{Variable measurement and data collection}

Data on the economic situation of households, including land, housing component structures and properties, sanitation, income, expenses, and liabilities, which is extracted from the Census data in 2014 by the GSO. Assets are classified by certain groups such as furniture, communication and electrical equipment, vehicles, and others. Sanitary conditions are rated as sources for drinking and cooking water, the toilet and the bathroom. All types of income were recorded to provide for the total income of a household. Daily food expenditures were multiplied for 30 days and added to the total monthly spending another to estimate total household spending monthly. Income and monthly expenses shall be divided by size of household.

The face to face interviews questionnaires were conducted by 10 trained staff. These include the question of support needed in daily activities, personal characteristics and families of the elderly, such as date of birth, gender, education, marital status, living arrangements, employment status, and the presence of chronic diseases. Three sizes of daily operations are applied when measuring the daily care needs, including basic daily activities such as bathing, dressing, using the toilet, transferring in and out of bed or a chair, writing, reading, listening to the radio, watching television. Support needs for each activity (no; some needs; totally dependent) were evaluated, along with the level of support received (no; not enough; enough) and care practitioners (son/daughter; grandchildren; relatives). The wording of the questions about this activity was carried out in line with Vietnam's context.

Then the group carried out a review of each question is completed and randomly selected $5 \%$ for re-interviewed. The question lacking or irrelevant value has been re-implemented. Data entry team with Epi-Data 3.1 was done to check the value is not suitable for each variable, and correct data entry errors based on actual data from the questionnaires.

\section{Statistical Analysis}

Data from the survey and the data extracted from the 2014 census are linked and analyzed using Stata 10. The index of family economic conditions, the index of household wealth was calculated as the first component of all economic variables from census. Household economic classification based on the hierarchy of all households. Status poverty households were classified using national poverty line for rural areas and based on the per capita income of 700,000 monthly (\$31.50) for the period 2015-2020. Poverty reflects the short-term economic conditions of households.

An index is calculated for each scale of daily operations by adding scores from each activity. Basic indicators of the daily activities range from 0 to 6 , the index and intellectual tools from 0 to 4 . Distribution of research participants by socio-economic groups, needs any support for each operation, the level of support received those with needs, the type of caregiver among those receiving support, and indicators of the daily activities described by the percentage and the corresponding 95\% confidence intervals.

Multivariate analysis using regression was performed to measure the impact of social and economic factors on the index daily activities. Female, aged 80 or older, illiterate, widowed, living without spouses or other family members, positions are members of households, do not work in old 
age is poorest group. A one-step process with a value of $p=5 \%$ for removal are used to identify important factors for maintaining a multivariate model formula

\section{Results}

Distribution of older by index daily activities for different age groups is shown in Table 1. Daily activities instrumental and intellectual are the most common problem, and whose frequency increases with age. The percentage of independents in the basic daily activities (index $=0$ ) decreased from $97.6 \%$ among those over 64 years to $86.7 \%$ among those over 84 years old. Nearly three-fifths of the elderly have problems with one or more daily activities in each scale. Most people depend for 1 or 2 daily activities or intellectual tool.

Necessary support for specific items in aged 60 years and above is described in Table 1 . The proportion of elderly people in need of help is highest for intellectual ADLs (13-32\%), followed by the tool ADLs (3-13\%), and basic ADLs (3-8\%). Reading and writing are the most common problems in intellectual ADLs. The most common problem in the tool ADLs is traveling and the most popular in the basic daily activities as bathing.

Table 1 Distribution of people aged 60 and older by the need to support the specific ADLs

\begin{tabular}{|c|c|c|c|c|c|c|c|}
\hline & Sample size & \multicolumn{2}{|c|}{ No need } & \multicolumn{2}{|c|}{ Some need } & \multicolumn{2}{|c|}{ Complete dependence } \\
\hline Type of ADL & & $\%$ & $95 \% \mathrm{CI}$ & $\%$ & $95 \% \mathrm{CI}$ & $\%$ & $95 \% \mathrm{CI}$ \\
\hline \multicolumn{8}{|l|}{ Basic ADLs } \\
\hline Bathing & 1,763 & 92.5 & $91.6-93.5$ & 5.3 & $4.5-6.1$ & 2.2 & $1.7-2.7$ \\
\hline Dressing & 1,763 & 95.5 & $94.8-96.3$ & 2.5 & $2.0-3.1$ & 2.0 & $1.4-2.5$ \\
\hline Toilet use & 1,763 & 96.6 & $95.9-97.2$ & 2.6 & $2.0-3.2$ & 0.8 & $0.5-1.2$ \\
\hline Transferring & 1,763 & 95.6 & $94.8-96.3$ & 3.1 & $2.5-3.8$ & 1.3 & $0.9-1.7$ \\
\hline \multicolumn{8}{|l|}{ Instrumental ADLs } \\
\hline Cleaning house & 1,456 & 97.2 & $96.6-97.9$ & 2.7 & $2.0-3.4$ & 0.1 & $-0.03-0.2$ \\
\hline Cooking & 1,254 & 96.4 & $95.6-97.2$ & 3.5 & $2.7-4.3$ & 0.1 & $-0.03-0.2$ \\
\hline Shopping & 754 & 96.6 & $95.6-97.6$ & 3.3 & $2.3-4.3$ & 0.2 & $-0.06-0.4$ \\
\hline Travelling & 1,256 & 86.8 & $85.3-88.2$ & 10.0 & $8.7-11.3$ & 3.2 & $2.5-4.0$ \\
\hline \multicolumn{8}{|l|}{ Intellectual ADLs } \\
\hline Writing & 858 & 71.8 & $69.5-74.2$ & 21.9 & $19.7-24.1$ & 6.3 & $5.0-7.6$ \\
\hline Reading & 1,013 & 67.9 & $65.6-70.1$ & 23.9 & $21.9-26.0$ & 8.2 & $6.9-9.5$ \\
\hline Listening to the radio & 1,627 & 86.8 & $85.6-88.1$ & 9.7 & $8.6-10.8$ & 3.5 & $2.8-4.2$ \\
\hline Watching TV & 1,609 & 83.4 & $82.0-84.8$ & 12.3 & $11.1-13.5$ & 4.3 & $3.5-5.1$ \\
\hline
\end{tabular}

Those who do care for ADL various sizes are described in Table 2. Children and grandchildren are primary caregivers. Children are the ones most often care for the basic daily activities and travel and have the same role in the intellectual activities and other tools. Support from the couple received only $9-12 \%$ of who need help with basic daily activities, less than 7\% supported the couple for ADLs tools and 5\% for intellectual ADLs. In addition, other caregivers, including relatives and neighbors, providing care is measured by most daily activities for less than $3.5 \%$ of the elderly; $26.8 \%$ excluding from neighbors, relatives to $7.3 \%$ from shopping, and $4.9 \%$ from relatives to travel. 
Table 2 Distribution of people aged 60 and older by the primary caregiver for the specific ADLs

\begin{tabular}{|c|c|c|c|c|c|c|c|}
\hline & & \multicolumn{2}{|c|}{ Son/daughter } & \multicolumn{2}{c|}{ Grandchild } & \multicolumn{2}{c|}{ Spouse } \\
\hline Type of ADL & Sample size & $\%$ & $95 \%$ CI & $\%$ & $95 \%$ CI & $\%$ & $95 \%$ CI \\
\hline Basic ADLs & & & & & & & \\
\hline Bathing & 218 & 80.7 & $75.5-86.0$ & 59.6 & $53.0-66.2$ & 11.9 & $7.6-16.3$ \\
\hline Dressing & 129 & 80.6 & $73.7-87.5$ & 56.6 & $47.9-65.3$ & 12.4 & $6.6-18.2$ \\
\hline Toilet use & 101 & 87.1 & $80.5-93.8$ & 64.4 & $54.9-73.9$ & 11.9 & $5.5-18.3$ \\
\hline Transferring & 130 & 74.6 & $67.0-82.2$ & 54.6 & $45.9-63.3$ & 9.2 & $4.2-14.3$ \\
\hline Instrumental ADLs & & & & & & & \\
\hline Cooking & 75 & 74.7 & $64.6-84.7$ & 80.0 & $70.7-89.3$ & 6.7 & $0.9-12.5$ \\
\hline Shopping & 42 & 57.1 & $41.5-72.8$ & 54.8 & $39.1-70.5$ & 0 & 0 \\
\hline Travelling & 268 & 96.3 & $94.0-98.6$ & 71.6 & $66.2-77.1$ & 0.8 & $-0.3-1.8$ \\
\hline Intellectual ADLs & & & & & & & $2.4-6.3$ \\
\hline Writing & 391 & 32.1 & $27.4-36.7$ & 25.6 & $21.2-29.9$ & 1.5 & $0.3-2.8$ \\
\hline Reading & 528 & 36.7 & $32.6-40.9$ & 37.5 & $33.4-41.6$ & 1.0 & $0.1-1.8$ \\
\hline Listening to the radio & 347 & 84.7 & $80.9-88.5$ & 86.5 & $82.8-90.1$ & 3.5 & $1.5-5.4$ \\
\hline Watching TV & 438 & 79.7 & $75.9-83.5$ & 82.2 & $78.6-85.8$ & 4.4 & 2.4 \\
\hline
\end{tabular}

Nearly $10 \%$ reported a need of some support in a basic daily activity, while more than $2 / 3$ is needed some assistance in an activity tool or intellectual. There are specific gaps in assistance needs by gender, education level, marital status, living arrangements, employment status, household size, area of residence, family economic conditions. Table 3 shows the relationship of these factors and socio-economic indicators with daily activities. Youth groups, literacy, marital status, work until old age, household sizes... are indicators that the daily activities at which is totally dependent on caregiver's support.

Table 3 The influence of socio-economic factors and the number of non-communicable diseases (NCDs) in the daily activities of living of elderly

\begin{tabular}{|c|c|c|c|c|c|c|c|c|c|}
\hline \multirow[t]{2}{*}{ Socioeconomic factors } & \multicolumn{3}{|c|}{ Basic ADLs } & \multicolumn{3}{|c|}{ Instrumental ADLs } & \multicolumn{3}{|c|}{ Intellectual ADLs } \\
\hline & Coef. & IRR & P-value & Coef. & IRR & $\mathrm{P}$-value & Coef. & IRR & P-value \\
\hline Aged 60-69 & $\begin{array}{c}-1.38 \\
2\end{array}$ & $\begin{array}{c}0.2 \\
5\end{array}$ & 0.002 & $\begin{array}{c}-0.71 \\
2\end{array}$ & $\begin{array}{c}0.4 \\
9\end{array}$ & $<0.001$ & $\begin{array}{c}-0.41 \\
5\end{array}$ & $\begin{array}{c}0.6 \\
6\end{array}$ & $<0.001$ \\
\hline Aged 70-79 & $\begin{array}{c}-1.38 \\
5\end{array}$ & $\begin{array}{c}0.2 \\
5\end{array}$ & $<0.001$ & $\begin{array}{c}-0.36 \\
6\end{array}$ & $\begin{array}{c}0.6 \\
9\end{array}$ & $<0.001$ & $\begin{array}{c}-0.16 \\
0\end{array}$ & $\begin{array}{c}0.8 \\
5\end{array}$ & $<0.001$ \\
\hline Male & & & & 0.424 & $\begin{array}{c}1.5 \\
3\end{array}$ & $<0.001$ & $\begin{array}{c}-0.37 \\
8\end{array}$ & $\begin{array}{c}0.6 \\
9\end{array}$ & $<0.001$ \\
\hline High school \& above & & & & $\begin{array}{c}-0.45 \\
9\end{array}$ & $\begin{array}{c}0.6 \\
3\end{array}$ & $<0.001$ & $\begin{array}{c}-1.99 \\
0\end{array}$ & $\begin{array}{c}0.1 \\
4\end{array}$ & $<0.001$ \\
\hline $\begin{array}{c}\text { Primary/secondary school } \\
\text { education }\end{array}$ & & & & $\begin{array}{c}-0.34 \\
7\end{array}$ & $\begin{array}{c}0.7 \\
1\end{array}$ & $<0.001$ & $\begin{array}{c}-0.81 \\
0\end{array}$ & $\begin{array}{c}0.4 \\
5\end{array}$ & $<0.001$ \\
\hline Able to read and write & & & & $\begin{array}{c}-0.24 \\
8\end{array}$ & $\begin{array}{c}0.7 \\
8\end{array}$ & $<0.001$ & $\begin{array}{c}-0.28 \\
4\end{array}$ & $\begin{array}{c}0.7 \\
5\end{array}$ & $<0.001$ \\
\hline Married & & & & & & & -0.17 & 0.8 & $<0.001$ \\
\hline
\end{tabular}




\begin{tabular}{|c|c|c|c|c|c|c|c|c|c|}
\hline & & & & & & & 6 & 4 & \\
\hline Separated/divorced/single & & & & 0.303 & $\begin{array}{c}1.3 \\
5\end{array}$ & 0.022 & & & \\
\hline Living with son/daughter & & & & 0.209 & $\begin{array}{c}1.2 \\
3\end{array}$ & 0.001 & & & \\
\hline Living with grandchild & & & & 0.152 & $\begin{array}{c}1.1 \\
6\end{array}$ & 0.002 & 0.083 & $\begin{array}{c}1.0 \\
9\end{array}$ & 0.026 \\
\hline Living alone & $\begin{array}{c}-2.69 \\
0\end{array}$ & $\begin{array}{c}0.0 \\
7\end{array}$ & 0.010 & $\begin{array}{c}-0.45 \\
2\end{array}$ & $\begin{array}{c}0.6 \\
4\end{array}$ & $<0.001$ & & & \\
\hline Working or employed & $\begin{array}{c}-2.53 \\
7\end{array}$ & $\begin{array}{c}0.0 \\
8\end{array}$ & 0.003 & $\begin{array}{c}-0.53 \\
0\end{array}$ & $\begin{array}{c}0.5 \\
9\end{array}$ & $<0.001$ & $\begin{array}{c}-0.17 \\
5\end{array}$ & $\begin{array}{c}0.8 \\
4\end{array}$ & $<0.001$ \\
\hline Living below NPL & & & & 0.094 & $\begin{array}{c}1.1 \\
0\end{array}$ & 0.012 & 0.090 & $\begin{array}{c}1.1 \\
0\end{array}$ & 0.019 \\
\hline Richest quintile & & & & & & & $\begin{array}{c}-0.41 \\
3\end{array}$ & $\begin{array}{c}0.6 \\
6\end{array}$ & $<0.001$ \\
\hline Richer quintile & & & & & & & $\begin{array}{c}-0.29 \\
7\end{array}$ & $\begin{array}{c}0.7 \\
4\end{array}$ & $<0.001$ \\
\hline Middle quintile & & & & & & & $\begin{array}{c}-0.21 \\
5\end{array}$ & $\begin{array}{c}0.8 \\
1\end{array}$ & $<0.001$ \\
\hline Poorer quintile & & & & & & & $\begin{array}{c}-0.17 \\
5\end{array}$ & $\begin{array}{c}0.8 \\
4\end{array}$ & $<0.001$ \\
\hline Number of NCDs & 0.634 & $\begin{array}{c}1.8 \\
8\end{array}$ & $<0.001$ & 0.067 & $\begin{array}{c}1.0 \\
7\end{array}$ & $<0.001$ & 0.074 & $\begin{array}{c}1.0 \\
8\end{array}$ & $<0.001$ \\
\hline Constant & $\begin{array}{c}-1.40 \\
0\end{array}$ & & $<0.001$ & 0.857 & & $<0.001$ & 1.295 & & $<0.001$ \\
\hline Pseudo R 2 & 0.245 & & & 0.153 & & & 0.200 & & \\
\hline
\end{tabular}

diseases (NCDs) in the daily activities of living of elderly .Coef. = coefficient; IRR = incident rate ratio; NPL = national poverty level; pseudo R2 = pseudo-coefficient of determination

\section{Discussion}

\subsection{Daily care needs in old age}

Functional disabilities are usually identified in the clinical research and community-based survey of older people by using ADLs. The findings of this study are based on the underlying index ADLs and support tools at the age of 65 and / or older. Proportion ADLs dysfunction of the elderly in the community is $2-8 \%$ and the elderly are more likely to depend on ADLs tool more basic ADLs. The whole depends on both ADLs and intellectually is much higher and faster increases with age for basic ADLs. This suggests that future interventions to improve the daily care for the elderly should focus on rural areas and in both the tools and intellectually functions, not on basic ADLs.

There is an unmet demand for support in ADLs while the main source of support for the care of the elderly is from children and grandchildren. This shows a clear demand of the model additional daily care outside the family. In the context of an increase in temporary migration of young labor force from rural to urban areas, this is particularly important. The need for the development of a social network service and long-term care for the elderly based on the community is lacking in rural Vietnam. Society organizations and members of the community at the grassroots level, along with medical experts in the current health system to be encouraged to participate in networks to fill the gaps of formal and not official care.

\subsection{Determinants personal care}

Men have a higher index for the ADLs basic and tools, while women only have a high ADLs intellectual index. This could be due to characteristics associated with patriarchy and patriarchal 
lineage also strongly affected in rural areas, and the fact that lower literacy rates among women. The first aspect may increase expectations about love between people help with ADLs basic and tools. Those who are separated divorced or single life is at risk group for ADLs tool index higher than widows in old age.

Demand for long-term care for the elderly with chronic diseases

The difference in the number of chronic diseases related to all ADLs index. Therefore, elderly with chronic diseases should be aiming to support care focuses on basic ADLs than intellectual and tools ADLs. This also shows the necessity of long-term care for people with chronic disease because basic ADLs include basic personal care. Common chronic disease in elderly, in long-term, care for the elderly will become a problem in rural areas.

\subsection{Methodological issues}

This is just a survey to explain the cause and effect relationship between the daily care needs and socio-economic factors, so there are many other factors that have not been considered. The presence of chronic disease may be underestimated because only the diagnosis of the doctors was recorded to be collected and reviewed.

\section{Conclusion}

Although older people who need help receive assistance in daily care, but care needs are greater than in the disadvantaged groups. Children and grandchildren are the main source of support for the elderly. Care needs are related closely to the age group, gender, educational level, marital status, family members, employment status, and residential area, the wealth of the family and the presence of chronic diseases. Further research to explain more clearly the relationship would be useful.

The development of a social network to improve care for the elderly based on the community is increasingly necessary. That system should focus on the intellectual and tool ADLs of older people, and on basic ADLs in older people with chronic disease.

\section{References}

[1] Barbieri M: Doi Moi and the elderly: Intergenerational support under the strain of reforms. Report at the 2006 Population of America Association Meeting, 2006, Los Angeles.

[2] Bowling A, Banister D, Sutton S, Evans O, Windsor J. A: Multidimensional model of the quality of life in older age. Aging Ment Health, 2002.

[3] Bui TC. Hanoi: In the space of social security: a research of the elderly in Vietnam. National University Press; 2005.

[4] Dodge BA: Primary healthcare for older people: A participatory study in 5 Asian countries. HelpAge International's Asia/Pacific Regional Development Centre (APRDC), 2008.

[5] Espelt A, Font-Ribera L, Rodriguez-Sanz M, Artazcoz La, Ferrando J, Plaza A, Borrell C: Disability Among Older People in a Southern European City in 2006: Trends in Gender and Socioeconomic Inequalities. Journal of Women's Health, 2010.

[6] Evans M, Gough I, Harkness S, McKay A, Huyen DT, Ngoc DLT: The relationship between old age and poverty in Viet nam. UNDP Vietnam, 2005.

[7] General Statistic Office. Report on Vietnam population projection, 2014-2049. Hanoi, 2015

[8] General Statistical Office: Population estimation for country, regions and 61 provinces/cities in Viet Nam, 2015.

[9] General Statistical Office. The 2014 Vietnam population and housing census: completed results, 2009.

[10] General Statistical Office: The population change and family planning survey, 2014.

[11] Haughton J. Geneva: Living standards during an economic boom (Vietnam 1993-1998), UNDP; 2001.

[12] Health Strategy and Policy Institute, Medical Publishing House: Assessment of health care for the elderly in Vietnam, 2007. 
[13] Kabir ZN, Parker MG, Szebehely M, Tishelman C: Influence of Sociocultural and Structural Factors on Functional Ability: The Case of Elderly People in Bangladesh. J Aging Health. 2001.

[14] Long GT, Pfau WD: The elderly population in Vietnam during economic transformation: an overview. Social issues under economic transformation and integration in Vietnam. Edited by: Long GT, Hong DK. 2007, Vietnam Development Forum

[15] McDowell I, Newell C. Oxford: Measuring health: a guide to rating scales and questionnaires, Oxford University Press; 1996.

[16] Minh HV, Ng N, Byass P, Wall S:Patterns of subjective quality of life among older adults in rural Vietnam and Indonesia. Geriatr Gerontol Int, 2012.

[17] Ministry of Health, Vietnam: Health Statistics Yearbook 2014.

[18] Nguyen PB, Hill PS:The role of temporary migration in rural household economic strategy in a transitional period for the economy of Vietnam. Asian Popul Stud, 2008.

[19] Nilsson J, Rana AM, Luong DH, Winblad B, Kabir ZN. Health-related quality of life in old age: a comparison between rural areas in Bangladesh and Vietnam. Asia Pac J Public Health, 2012.

[20] United Nations Development Programme. Vietnam at a glance. Available from:http://www.undp.org.vn/undpLive/Content/UNDP/About-Viet-Nam/Viet-Nam-at-a-Glance 